\title{
EMOÇÕES SÃO MESMO INTENCIONAIS? \\ CONSIDERAÇÕES PARA UMA \\ TEORIA ADVERBIAL DAS EMOÇÕES
}

\section{Veronica de Souza Campos ${ }^{1}$}

\begin{abstract}
RESUMO
Esse é um texto sobre o que são emoções e sobre como estados ou eventos emocionais se distinguem de outros estados ou eventos. O problema de o que são emoções é frequentemente abordado como pressupondo a noção de intencionalidade, isto é, como pressupondo que estados ou eventos emocionais sejam sobre algo. Se por um lado essa ideia corresponde a uma intuição ordinária, por outro lado teorias que se baseiam nela frequentemente têm consequências pouco desejáveis, tais como, por exemplo, a ideia de que emoções requerem um componente judicativo intelectual e, portanto, de que emoções são estados ou eventos que só podem ser experimentados por criaturas dotadas de capacidades intelectuais. É possível desafiar a tese de que emoções são intencionais? Nesse artigo pretendo abordar essa questão, cotejando, de maneira breve e modesta, a tese de que emoções não são intencionais e vislumbrando uma alternativa positiva.
\end{abstract}

Palavras-chave: Emoções. Intencionalidade. Teoria adverbial das emoções.

\begin{abstract}
This is a text about what emotions are and how emotional states or events are distinguished from other states or events. The problem of what emotions are is often approached as assuming the notion of intentionality, that is, as assuming that emotional states or events are about something. If, on the one hand, this idea corresponds to an ordinary intuition, on the other hand theories that are based on it often have undesirable consequences, such as, for example, the idea that emotions require an intellectual judicative component and, therefore, that emotions are states or events that can only be experienced by creatures with intellectual capacities. Is it possible to challenge the thesis that emotions are intentional? In this article I intend to address this issue, considering, in a brief and modest way, the thesis that emotions are not intentional and envisioning a positive alternative.
\end{abstract}

Keywords: Emotions. Intentionality. Adverbial theory of emotions.

\footnotetext{
${ }^{1}$ Bacharel e mestre em Filosofia pela UFMG. Doutoranda no Programa de Pós-Graduação em Filosofia da UFMG.182vkai@gmail.com.
} 


\section{Introdução}

É tipicamente tomada como certa a tese de que emoções são intencionais, viz., de que elas são sobre algo (Pitcher, 1965). A ideia de "intencionalidade", de inspiração fenomenológica, costuma ser entendida como a propriedade segundo a qual há uma "orientação", "direcionamento" ou "representação" de uma atitude ou estado mental em relação a determinada coisa ou estado de coisas (um objeto). Um estado ou atitude $\boldsymbol{e}$ é dito intencional se pressupõe um objeto intencional $\boldsymbol{O}(\boldsymbol{e}$ é a respeito de $\boldsymbol{O}$, ou é dirigido para $\boldsymbol{O}$, ou representa $\boldsymbol{O}$ ). Assim, para uma atitude $\boldsymbol{e}$, ter um objeto intencional $\boldsymbol{O}$ é ter algo sobre o quê (num desses três sentidos de "sobre") ela é. Dizemos, por exemplo, que a crença de que choveu em Belo Horizonte no carnaval de 2020 e a crença de que vitamina $\mathrm{C}$ faz bem à saúde são ocorrências que envolvem a mesma atitude (crer), mas que diferem uma da outra precisamente porque seus objetos intencionais são distintos: a primeira é sobre chuva (ou sobre ter chovido em Belo Horizonte no carnaval de 2020) enquanto a segunda é sobre vitamina (a ideia de que vitamina $\mathrm{C}$ é benéfica à saúde). Do mesmo modo, imaginar um sorvete de flocos e desejar um sorvete de flocos são duas atitudes diferentes (imaginação e desejo) com um mesmo objeto intencional (ambas são sobre aquele sorvete).

Os defensores da tese de que emoções são intencionais citam comumente a título de exemplo eventos como o medo e a raiva: quando temos medo, temos medo de algo; quando temos raiva, temos raiva de algo, etc. Ou seja, medo e raiva (emoções em geral) seriam atitudes ou estados intencionais, já que, aparentemente, sempre são de algo. Embora algumas emoções certamente sejam intencionais na medida em que possuem objetos intencionais claramente definidos, sendo essa uma tese pouco controversa, ainda é uma pergunta em aberto se toda emoção é intencional. Essa é a pergunta sobre se a intencionalidade - a existência de algo a respeito do qual se pode dizer que o estado ou atitude em questão é sobre - é ou não uma condição para a ocorrência de emoções.

Com efeito, um exame rápido nos permite observar que possuir um objeto intencional não parece qualificar como condição suficiente à caracterização de uma ocorrência como sendo uma ocorrência emocional (haja vis- 
ta que outras ocorrências mentais/corporais são tipicamente entendidas como sendo intencionais mas não como sendo emoções - é o caso por exemplo de crenças, tais como as que citamos acima, bem como de desejos, juízos, dentre outros). Então resta examinar se a posse de um objeto intencional é ou não uma condição necessária à caracterização de uma ocorrência como sendo uma emoção.

\section{A tese da necessidade e suas variações}

Emoções costumam ser identificadas com uma certa excitação (arousal) que ocorre no organismo a nível corporal, visceral; algo que é da ordem de uma afetação ou sensação. A excitação tipicamente envolve algo que é apreciado de uma determinada maneira que tem um impacto (i.e., que é relevante) para o bem-estar do organismo (appraisal), de modo que essa apreciação é normalmente entendida como possuindo um objeto, ao passo que o sentimento de excitação que ela provoca, propriamente dito, não possui $^{2}$. Dito de outro modo: o appraisal é normalmente entendido como sendo intencional, ao passo que o arousal é entendido como não sendo. Se a emoção for identificada ao arousal, àquilo que é sentido no corpo, então a pergunta sobre se emoções são ou não intencionais na realidade é a pergunta sobre qual a relação entre essa sensação, o arousal, e o juízo avaliativo correspondente, o appraisals. Appraisals provocam arousals? Ou appraisals participam de arousals?

Desse modo, a pergunta sobre se ser intencional é ou não parte do que é ser uma emoção admite basicamente duas possibilidades de entendimento: ou bem a intencionalidade (que é característica da apreciação de um objeto) entra na emoção como um componente, i.e., como um elemento constitutivo (Pitcher 1965); e nesse caso o que está sendo perguntado é se se trata de um elemento realmente necessário, sem o qual o evento não pode ser considerado uma emoção; ou bem a intencionalidade entra na emoção a título de antecedente causal, sendo imprescindível para desencadeá-la, mas não participando em seu escopo mesmo (Prinz, 2004); e nesse caso o que

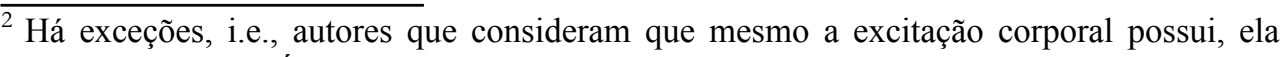
própria, um objeto. É o caso por exemplo de Goldie (2000).
} 
está sendo perguntado é se se trata de um antecedente necessário, sem o qual a emoção não vem a ser.

Em suma, a tese de que possuir um objeto intencional é uma condição necessária à caracterização de uma ocorrência como sendo uma emoção pode ser redesenhada de duas maneiras e, graças a isso, pode ser desafiada de duas maneiras, conforme abaixo:

i. a existência de um objeto intencional é um elemento constitutivo da emoção. (Mas o é necessariamente?)

ii. a existência de um objeto intencional é um antecedente causal da emoção.

(Mas o é necessariamente?)

A sobrevivência da ideia de que intencionalidade é uma condição necessária à emoção está na dependência de que a empreitada de desafiar cada uma dessas duas possibilidades de entendimento fracasse.

Desafiar (i) não é muito difícil, já que essa possibilidade é problemática por duas razões muito claras: primeiro, ela parece implicar que é parte do que é uma emoção ser dirigida a objetos no mesmo sentido que (i.e., do mesmo modo como) estados intencionais paradigmáticos, como crenças e juízos, são dirigidos a seus respectivos objetos. Embora essa ideia tenha ampla aceitação entre filósofos e psicólogos, ela não é universalmente acei$\operatorname{ta}^{3}$. O motivo é basicamente o fato de que há uma diferença relevante entre os estados intencionais paradigmáticos e as emoções; uma diferença que tem um impacto sobre a atribuição do caráter intencional enquanto propriedade essencial: estados intencionais paradigmáticos são tipicamente atitudes proposicionais, viz., atitudes que tem como objeto um estado de coisas que pode ser expresso na forma de uma sentença dotada de valor de verdade (aquilo que é capturado pela expressão inglesa "that-clause"), ao passo que isso não parece ser o caso para emoções. Não parece muito palatável, tampouco claro, que emoções sejam atitudes proposicionais no sentido robusto. Se por um lado parece aceitável que em "X julga que $\boldsymbol{p}$ " ou "X crê que $\boldsymbol{p}$ ", $\boldsymbol{p}$ seja uma proposição na medida em que é algo que $\mathrm{X}$ toma como verdadeiro, o mesmo não parece fazer muito sentido para "X emociona que $\boldsymbol{p}$ ", ou mesmo para formulações mais específicas (envolvendo emoções específicas), do tipo "X teme que $\boldsymbol{p}$ ", por que nessas atitudes (emocionar-se e temer) $\mathrm{X}$ não

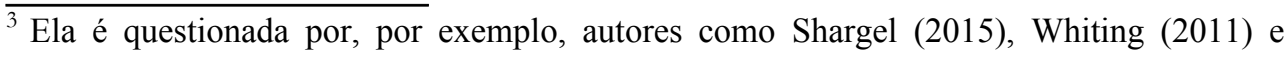
Reisenzein (2012). 
atribui ao objeto $\boldsymbol{p}$, ou ao menos não precisa atribuir, nenhum valor de verdade. Esse é o principal problema com (i).

Um problema adicional com (i) é que essa hipótese tem a consequência desagradável de fazer com que certos estados afetivos que nós tipicamente tomamos como pertencendo ao domínio das emoções (ou pelo menos como não sendo muito claramente distintos delas) deixem de poder ser classificados como tal - é o caso, por exemplo, da alegria e da tristeza, mas também de outros, como angústia, a melancolia, vergonha e a paz interior; estados que parecem não ter um objeto intencional constitutivo muito claramente definido, ou ao menos não um que pareça ser realmente necessário para sua caracterização específica, embora frequentemente possamos identificar um como sendo sua causa. Por exemplo, posso estar alegre sem estar alegre sobre nada específico (nos três sentidos de "sobre" que indicamos no começo), ou mesmo sem que minha alegria seja em torno de um motivo específico. Esse estado emocional certamente tem uma causa, e frequentemente tem uma causa específica - ele pode ter sido causado por uma droga, por exemplo, ou pela minha apreciação geral da vida como estando em ordem, i.e., minha crença de que tudo vai bem. A droga (ou a minha crença de que tudo vai bem) me faz ficar alegre, mas a minha alegria não é sobre a droga, nem sobre aquela crença. Minha alegria é algo que eu simplesmente sinto. O mesmo parece valer para os demais estados que indicamos.

Já (ii) pode ser desafiada a partir do seguinte: se o appraisal for meramente um antecedente causal, mas não um componente, da emoção, então parece que a relação entre o objeto intencional do appraisal e a emoção propriamente dita passa a requerer um juízo valorativo ou, pelo menos, uma espécie de conteúdo cognitivo. Quer dizer, se a apreciação de uma cobra como "perigosa" ou como "uma ameaça ao meu bem estar" só entra na economia do medo a título de agente deflagrador (causa), mas não faz parte do medo mesmo, então parece que se torna difícil explicar como essa relação causaefeito se dá, i.e., como a apreciação da cobra é capaz de fazer disparar a excitação que é típica do medo (emoção propriamente dita), a menos que se recorra a juízos ou outras operações cognitivas de caráter representacional ou quase-representacional, sob pena de esse mecanismo de causação permane- 
cer um tanto quanto misterioso. Isto é, parece que precisamos postular algo do tipo:

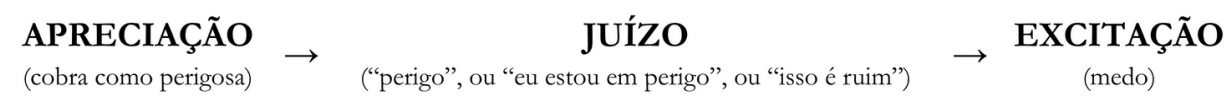

do contrário (viz., se não tivermos o juízo ou algo que o valha) a mera apreciação parece insuficiente para causar excitação - com efeito, nós experimentamos, na nossa vida comum, um sem-número de situações nas quais nós apreciamos itens relevantes para o nosso bem-estar sem que essa apreciação seja seguida de qualquer excitação. Num dia frio eu aprecio, por exemplo, um agasalho (positivamente) como relevante para o meu bem-estar, mas essa apreciação não é seguida por nada que mereça ser qualificado como excitação ou emoção. Ou então, por exemplo, ao me aproximar para ver uma cobra que se encontra isolada de mim por uma redoma de vidro, como é comum nos zoológicos, eu a aprecio como perigosa (e, por isso, como tendo um impacto negativo sobre o meu bem-estar), mas disso não resulta um medo, nem sequer um estado de excitação, precisamente porque naquela situação eu não julgo que estou em perigo. Assim, a hipótese de que o appraisal entre na ocorrência emocional a título de antecedente causal, mas não de componente constitutivo, nos força a uma explicação relativamente intelectualista do mecanismo causal subjacente à emoção, sendo isso uma espécie de ponto fraco dessa hipótese. Se alguém tem um interesse genuíno em evitar abordagens intelectualistas ou cognitivistas das emoções, parece que essa pessoa está no dever de abrir mão da ideia de que os objetos intencionais dos appraisals podem, por si mesmos, provocar arousals.

\section{A estratégia de Jesse Prinz}

Aqueles que subscrevem a (ii), como Prinz (2004), que é autor da teoria segundo a qual emoções são avaliações incorporadas ("embodied appraisals"), frequentemente tentam conciliar os dois interesses, i.e., o interesse em desenvolver uma abordagem não-intelectualista ou não-cognitivista das emoções e o interesse em manter a ideia de que emoções possuem objetos intencionais - eles relutam em postular a existência do juízo, do qual 
falamos, ou de algo equivalente, aparentemente, na justa medida em que isso torna a explicação mais dependente de conteúdos cognitivos do que se gostaria de admitir. Prinz ensaia uma explicação de acordo com a qual a própria apreciação da cobra, por si mesma, é suficiente para desencadear o medo à maneira inteiramente causal, sem envolver nenhum julgamento, e mesmo sem envolver conceitos (ele acredita que o conteúdo dessa apreciação é do tipo não conceitual ${ }^{4}$ ). Após um exame mais refinado, contudo, essa estratégia não parece muito bem-sucedida. Vamos ver como.

Prinz lança mão de uma distinção entre objeto formal (que é constitutivo da emoção na medida em que é o seu tema) e o objeto particular (que não é constitutivo da emoção e sim seu agente causador ${ }^{5}$ ). Se, por exemplo, estou de luto pela morte de uma criança, a emoção (luto) tem um objeto particular, que é a morte daquela criança particular; e um objeto formal (um core relational theme do luto, em geral), que é a perda. Já no caso do medo, por exemplo, em relação a uma cobra, o objeto particular é a própria cobra (aquela cobra particular) enquanto o objeto formal (o core relational theme do medo) é a ameaça. E assim por diante, cada emoção tendo um tema central próprio ${ }^{6}$ e requerendo um item particular para ser eliciada. Segundo Prinz, a atitude do indivíduo em relação ao objeto particular - o ato de perceber a cobra, digamos assim, no caso do medo - é uma atitude cujo conteúdo é do tipo não conceitual. Cobras são perigosas, independentemente de o sujeito as apreciar como tal, viz., independentemente de o sujeito aplicar ou não, a uma cobra particular, o rótulo "perigosa". Por outro lado, a atitude do indivíduo em relação ao objeto formal é uma atitude que envolve exercitar o conceito de "ameaça", no caso do medo, ou o conceito de perda, no caso do luto, ainda que não verbalmente ou não-proposicionalmente (graças a isso é uma atitude cujo conteúdo, podemos dizer, é necessariamente do tipo conceitual). Agora, a pergunta é: como, exatamente, o ato de perceber uma cobra que não a classifica de nenhum modo pode desempenhar um papel

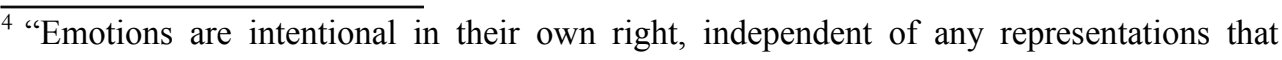
happen to accompany them. This is where Kenny's formal objects come in. Sadness represents the loss of something valued. If I am sad about the death of a child, I have one mental representation that corresponds to the child's death and another, my sadness, that corresponds to there having been a loss". Cf. Prinz, pp. 62-63.

5 "Saying that my sadness is about the death does not mean that my sadness represents the death; rather it means that the death is what has caused me to become sad". Ibid, pp. 62-63.

${ }^{6}$ Seguindo de maneira mais ou menos fiel a caracterização de Lazarus (1991).
} 
eliciador (causal) em relação à atitude que o sujeito adota para com o core relational theme? Como a mera apreciação não-conceitualmente mediada que eu faço de uma cobra particular pode me colocar numa certa relação com um conceito geral, a saber, o conceito de ameaça? A menos que haja uma ordem imanente na natureza que faça com que cobras invariavelmente causem representações de ameaça, isso não parece muito plausível ou, no mínimo, permanece um mistério. Admitir que haja uma ordem imanente na natureza que faça com que cada cobra não-classificada como ameaçadora invariavelmente cause representações de ameaça é admitir que há uma ordem imanente na natureza segundo a qual a cada coisa mesma corresponde certo conceito (ou conceitos), cuja representação a coisa tem a função de causar, mas que ela própria não é tomada como instanciando. Significa ter de admitir que o conceito AMEAÇA guarda uma relação natural de correspondência em relação a um conjunto finito de coisas do qual cobras fazem parte e existe per se, i.e., existe como tal independentemente de estar instanciado por essas coisas (sabe-se lá onde; talvez no terceiro domínio fregeano). Isso não parece muito crível, porque a relação entre o conceito AMEAÇA e uma cobra particular não parece ser do mesmo tipo da relação que há entre, por exemplo, fumaça e fogo. Fumaça indica fogo, na medida em que o fogo, por si mesmo, é uma causa natural da fumaça. Uma cobra particular só pode indicar ameaça do mesmo modo como fumaça indica fogo se o conceito de AMEAÇA estiver, para a cobra, do mesmo modo como o fogo está para a fumaça - isto é, se o conceito de AMEAÇA tiver uma espécie de antecedência ou prioridade em relação à cobra; se for ele, por si mesmo, o causador da cobra; o que é absurdo.

Talvez possamos ser mais caridosos com Prinz concedendo que cobras instanciam a propriedade "ser perigosas" independentemente de nossas atitudes para com elas, do que pensamos sobre elas, ou de as termos percebido. Ainda assim, para sentir medo de uma cobra particular é preciso tê-la percebido ou, pelo menos, tê-la imaginado (não posso ter medo de uma cobra particular que não está presente para mim nem física nem mentalmente, porque é a cobra enquanto objeto particular que elicia a emoção medo). Porém, se ao perceber ou imaginar uma cobra particular eu não aplico conceito algum, como essa percepção/imaginação pode eliciar uma relação envolven- 
do uma representação conceitual (seu core relational theme); uma emoção que envolve precisamente o conceito de "ameaça"? E, ainda que não seja a percepção da cobra que elicie a minha relação com o conceito "ameaça", i.e., ainda que não seja a minha atitude para com o objeto particular que elicie a minha atitude para com o objeto formal, como explicar o fato de que essas relações ocorrem em paralelo? Perceber não-conceitualmente uma cobra particular e, em consequência (ou em paralelo), entrar numa relação com um objeto intrinsecamente conceitual - a noção de ameaça - não pode ser, afinal de contas, relevantemente diferente de perceber uma cobra e tomá-la como significando ou representando perigo. Pois o que é, afinal, “entrar numa relação com a noção de ameaça" senão precisamente adotar uma atitude cognitiva, de tomar tal-e-tal como sendo o caso (julgar mesmo "essa cobra é uma ameaça", ou "eu estou em perigo")? Prinz só substituiu o componente judicativo (a noção dura de juízo, na fórmula que havíamos desenhado acima) pela instauração, digamos, instantânea, de uma relação representacional-conceitual para com o tema (que no exemplo do medo é a noção de "ameaça") mas que na realidade está muito pouco aquém de um juízo propriamente dito. Portanto mesmo no framework de Prinz uma espécie de conteúdo cognitivo entra "pela porta dos fundos" na caracterização da emoção; tem de entrar, sob pena de não conseguirmos explicar como apreciações, que são intencionais, podem reter algum poder causal.

\section{Uma abordagem alternativa}

Se é uma abordagem não-cognitivista ou não-intelectualista da emoção que queremos, então parece que chegamos a uma espécie de puzzle. Ambas as versões da tese de que emoções são necessariamente intencionais parecem ser fontes de problemas tanto quanto são informativas. Assim, além da dificuldade intrínseca ao reconhecimento da intencionalidade como condição suficiente à emoção, a ideia de que ela seria uma condição necessária - mesmo em sua versão mais soft, especificada por (ii) - também só pode ser assumida a um alto custo: ela exige a postulação de que há conteúdos cognitivos em operação na captação do objeto intencional. Será que essa tese deve então ser abandonada? Mas, nesse caso, como fica a intuição bási- 
ca (e forte) que temos de que emoções são tipicamente sobre algo? Deve também ser posta de lado?

$\mathrm{Na}$ verdade, há uma maneira alternativa de preservar essa intuição sem que precisemos nos comprometer com nenhuma das duas versões da tese de que emoções são intencionais. Essa maneira consiste de considerar que, quando dizemos que medo é sempre medo de algo, ou que raiva é sempre raiva de algo, etc., o "de" que está em jogo ali não é o "de" de intencionalidade. Quer dizer, esse "de" não é o "de" que indica direcionamento a um objeto, e sim um "de" que indica um outro tipo de relação não-cognitiva. Trata-se de um tipo de relação temática pré-judicativa: aquilo que os intencionalistas (partidários da ideia de que emoções são intencionais) acreditam ser o objeto intencional da emoção é, de acordo com essa caracterização alternativa, o seu motivo. "Motivo" deve ser entendido aqui no sentido trivial de "assunto de composição", i.e., mais ou menos no mesmo sentido que temos em mente quando dizemos, por exemplo, que determinado tecido tem um motivo floral na medida em que é estampado com imagens de flores, ou que uma sonata tem um motivo fúnebre na medida em que seu tom nos remete a uma atmosfera lúgubre e soturna, ou mesmo quando dizemos que determinada canção é a "canção-tema" de certo personagem numa peça dramatúrgica, na medida em que essa canção entra como música de fundo (trilha sonora) todas as vezes que o personagem aparece em cena ou em que seus dramas são trazidos à tona. Se tenho uma peça de tecido floral ou uma sonata fúnebre nesse sentido específico que acabamos de indicar, a relação que há entre tecido e flor, bem como a relação que há entre sonata e clima fúnebre, não é nem de "orientação", nem de "direcionamento", nem de "representação" (ao menos não no sentido tradicional em que representar envolve tomar um certo estado de coisas como sendo tal-e-tal e adotar em relação a ele uma atitude específica) - ou seja, não é uma relação de intencionalidade, em nenhum dos sentidos típicos que essa ideia possui. Não obstante, é válido argumentar que aquilo que a flor é para uma peça de tecido floral é análogo àquilo que a ameaça é para o medo, ou que a perda é para o luto: ter medo de uma cobra ou luto pela perda de uma criança é estar, em relação ao "motivo" (o core relational theme de cada uma dessas emoções) no tipo de estado que instancia essa relação pré-judicativa de tematização. 
Essa caracterização alternativa coaduna com (e na realidade pressupõe) o framework de uma teoria alternativa capaz de explicar como exatamente o objeto particular que está ligado à emoção se relaciona com o motivo, ou tema, sem tomá-lo como objeto intencional. Essa teoria deve ser uma teoria adverbial da emoção.

Teorias adverbiais se tornaram conhecidas na literatura dita analítica sobretudo a partir de sua exploração no domínio da percepção, como alternativas ao paradigma sujeito-objeto ${ }^{7}$; embora elas também possuam margem para ser redefinidas para o âmbito das emoções ${ }^{8}$. O insight por trás das teorias adverbiais é compartilhado com a fenomenologia, ou seja, vem do mesmo "berço" de onde veio a noção de intencionalidade - a ideia de que aquilo que está sendo percebido ou sentido não pode existir quando não estiver sendo percebido ou sentido por alguém. Porém o framework elementar das teorias adverbiais é ligeiramente diferente: elas buscam redefinir as sentenças que são sobre aquilo que é percebido ou sentido como dizendo respeito ao modo como algum indivíduo está percebendo ou sentindo. Assim, grosso modo, se considerarmos, por exemplo, uma situação em que há um sujeito percipiente $\boldsymbol{S}$ e uma maçã vermelha, enquanto o intencionalista dirá que $\boldsymbol{S}$ percebe a maçã vermelha, sendo a cor vermelha uma propriedade do objeto intencional na ação de perceber, o adverbialista dirá que $\boldsymbol{S}$ percebe a maçã vermelhamente, sendo a cor não uma propriedade do objeto e sim o modo como o indivíduo vivencia sua ação de perceber. No caso específico de emoções, essa teoria consiste de redefinir emoções como sendo a maneira particular como determinado indivíduo vive determinada experiência; realiza ou sofre determinada ação.

A principal vantagem dessa maneira alternativa de compreensão é que nela a emoção deixa de ser uma atitude proposicional específica e, com isso, o problema em torno da sua suposta intencionalidade (i.e., o problema com as teses que lhe atribuem intencionalidade e que, como viemos, são teses cujo sustento envolve um alto custo) se dissolve. A emoção passa a ser vista como sendo a maneira particular como uma atitude a (qualquer que seja: perceber, imaginar, crer, etc.) é experimentada ou vivida pelo indiví-

\footnotetext{
${ }^{7}$ Ver por exemplo Sellars (1975).

${ }^{8}$ Ver por exemplo o trabalho de Berninjer (2016).
} 
duo. Graças a isso, essa é uma abordagem menos intelectualista ou, pelo menos, menos cognitivamente demandante - ela não requer nenhum juízo ou conteúdo cognitivo mediando nossa relação com o agente causador (ou com o objeto intencional) da atitude $\boldsymbol{a}-$ a atitude $\boldsymbol{a}$ pode até mesmo ser uma ação irrefletida, que é afetivamente "colorida" de um modo ou de outro. Em outras palavras, aquilo que chamamos de arousal nem é provocado pelo appraisal nem o possui como elemento constituinte, como havíamos cotejado no começo - o arousal é, antes, a maneira particular como o appraisal se dá subjetivamente. Graças a isso não é preciso explicar como appraisal e arousal se relacionam - eles não são duas 'coisas' distintas que precisam ser unidas por um mecanismo (causal, representacional, ou outro, seja como for). Eles são, na verdade, uma só e a mesma coisa; quer dizer, só há uma coisae essa coisa sempre é vivida de uma certa maneira. A emoção corresponde a essa maneira.

Além disso, na justa medida em que nessa compreensão alternativa a emoção deixa de ser equacionada com uma atitude propriamente dita $\mathbf{a}$ e se torna o "colorido peculiar", digamos assim, da experiência subjetiva de a, essa abordagem tem chances de atingir um grau maior de fidedignidade em relação às nossas experiências mesmas. Muito embora uma teoria adverbial da emoção não capture o modo como nós falamos ordinariamente (nós não falamos, no nosso idioleto vulgar, que "experimentamos uma cobra medrosamente"), a verdade é a que forma tradicional como nós nos referimos à emoção ("temos medo de $\boldsymbol{x}$ ') se aproxima consideravelmente menos da maneira como as coisas efetivamente se dão para nós do que a elocução alternativa. A elocução tradicional "ter medo de $\boldsymbol{x}$ ” não explicita, não põe em relevo o core relational theme da emoção, que é o que realmente caracteriza e individua a emoção, de modo que é como se as elocuções desse tipo expressassem o core relational theme apenas indireta ou implicitamente. Assim, uma abordagem adverbial parece capturar algo de muito verdadeiro a respeito do que são emoções, algo que as abordagens intencionais parecem deixar de fora: o fato de que na prática o core relational theme é precisamente o traço da emoção em destaque; é a sua marca fenomenológica dotada de maior relevo. O que distingue uma situação onde "eu vejo $\boldsymbol{x}$ ” de uma situação onde "eu tenho medo de $\boldsymbol{x}$ " é justamente o fato de que a segunda é 
afetivamente carregada, ou emocionalmente encharcada, digamos assim, pela ameaça, ou pelo tema da ameaça.

\section{Considerações Finais}

À luz do que foi exposto, é justo considerar que uma abordagem adverbial da emoção pode constituir uma alternativa viável às abordagens intencionais, além de ser uma abordagem econômica e interessante. Longe de pretender dar como acabada a análise dessa alternativa, cabe-nos apenas salientar que, com base no que foi indicado, se devidamente explorada, uma tal abordagem teria permitido a um autor como Prinz (2004) uma descrição consideravelmente menos intelectualista acerca da natureza das emoções do que aquela (intencionalista) que é avançada por ele. Abordagens intencionalistas como a de Prinz tornam difícil compreender como criaturas não-dotadas de capacidades intelectuais podem experimentar emoções, ou seja, parecem tornar a emoção um traço exclusivamente humano. Nesse sentido, uma das principais vantagens de uma teoria adverbial seria a de desvincular o componente judicativo-intelectual da experiência emocional, tornando mais fácil acomodar a intuição básica compartilhada por muitos segundo a qual emoções são mais um ponto de convergência entre animais humanos e animais não-humanos (isto é, algo que compartilham) do que uma diferença fundamental entre eles.

\section{Referências bibliográficas}

BERNINGER, Anja. Thinking sadly: In favor of an adverbial theory of emotions. In: "Philosophical Psychology", 2016. Disponível em:

$<\underline{\text { http://dx.doi.org/10.1080/09515089.2016.1159294>. }}$

DE SOUSA, Ronald. Emotion. In: "The Stanford Encyclopedia of Philosophy" (Winter 2017 Edition), Edward N. Zalta (ed.). Disponível em: $<$ https://plato.stanford.edu/archives/win2017/entries/emotion/ $>$.

GOLDIE, Peter. The emotions. New York: Oxford University Press, 2000.

LAZERUS, Richard. Emotion and adaptation. New York: Oxford University Press, 1991.

PITCHER, George. Emotion. In: “Mind”, n. 74, 1965, pp. 324-346. 
PRINZ, Jesse. Gut reactions: A perceptual theory of emotions. Oxford: Oxford University Press, 2004.

REISENZEIN, Rainer. What is an emotion in the belief-desire theory of emotion? In PAGLIERI, F.; TUMMOLINI, L.; MICIELI, M. (Eds.) "The goals of cognition: Essays in honor of Cristiano Castefranchi". London: College Publications, 2012, pp. 181-211.

SELLARS, Wilfrid. The adverbial theory of the objects of perception. In: "Metaphilosophy", n.6, 1975, pp. 144-160.

SHARGEl, Daniel. Emotions without objects. In: "Biology and Philosophy”. n. 30, v.6., 2015, pp.831-844.

SANDER, D.; SCHERER, K. R. (Eds.). The Oxford companion to emotion and the affective sciences. Oxford: Oxford University Press, 2009.

WHITING, Demian. The feeling theory of emotion and the object-directed emotions. In: "European Journal of Philosophy", n.19, 2001, pp. 281-303. 